Full length article

\title{
The Social Media Disorder Scale
}

\author{
Regina J.J.M. van den Eijnden ${ }^{\text {a, }}{ }^{*}$, Jeroen S. Lemmens ${ }^{b}$, Patti M. Valkenburg ${ }^{c}$ \\ a Interdisciplinary Social Science, University of Utrecht, Heidelberglaan 1, 3584 CS, Utrecht, The Netherlands \\ b Amsterdam School of Communication Research, University of Amsterdam, Nieuwe Achtergracht 166, 1001 NG, Amsterdam, The Netherlands \\ ${ }^{\mathrm{c}}$ Amsterdam School of Communication Research, University of Amsterdam, Spui 21, 1012 WX Amsterdam, The Netherlands
}

\section{A R T I C L E I N F O}

\section{Article history:}

Received 9 December 2015

Received in revised form

10 March 2016

Accepted 11 March 2016

Available online 25 March 2016

\section{Keywords:}

Social Media Disorder

Social media addiction

Problematic social media use

Pathological social media use

Social media use

Internet addiction

\begin{abstract}
A B S T R A C T
There is growing evidence that social media addiction is an evolving problem, particularly among adolescents. However, the absence of an instrument measuring social media addiction hinders further development of the research field. The present study, therefore, aimed to test the reliability and validity of a short and easy to administer Social Media Disorder (SMD) Scale that contains a clear diagnostic cutoff point to distinguish between disordered (i.e. addicted) and high-engaging non-disordered social media users.

Three online surveys were conducted among a total of 2198 Dutch adolescents aged 10 to 17 . The 9item scale showed solid structural validity, appropriate internal consistency, good convergent and criterion validity, sufficient test-retest reliability, and satisfactory sensitivity and specificity. In sum, this study generated evidence that the short 9-item scale is a psychometrically sound and valid instruments to measure SMD.
\end{abstract}

๔ 2016 The Authors. Published by Elsevier Ltd. This is an open access article under the CC BY-NC-ND license (http://creativecommons.org/licenses/by-nc-nd/4.0/).

\section{Introduction}

The research field of Internet addiction continues to suffer from definition and measurement problems. The concept Internet addiction, also referred to as compulsive (Meerkerk, Van den Eijnden, Vermulst, \& Garretsen, 2009) or problematic Internet use (Caplan, 2010), is multi-dimensional by nature and can refer to different forms of compulsive online behaviors. Individuals do not seem to be addicted to the Internet itself, but rather to certain online activities (Griffiths \& Szabo, 2013). Some of these activities, however, appear to elicit more compulsive tendencies than others. Among adolescents, the age group that rapidly adopts new technologies and is expected to be most vulnerable to possible negative influences of these new technologies (Valkenburg \& Peter, 2011), Internet addiction has most convincingly been linked to gaming and to social media use (Rumpf, Meyer, Kreutzer, John \& Meerkerk, 2011; Van Rooij, Schoenmakers, Van den Eijnden, \& Van de Mheen, 2010). Although the latest version of the Diagnostic and Statistical Manual of Mental Disorders (DSM-5) recognizes Internet gaming disorder as a tentative disorder in the appendix of this manual

\footnotetext{
* Corresponding author. Department of Interdisciplinary Social Science, Utrecht University, P.O. Box 80140, 3508 TC Utrecht, The Netherlands.

E-mail addresses: R.J.J.M.vandenEijnden@uu.nl (R.J.J.M. van den Eijnden), j.s. lemmens@uva.nl (J.S. Lemmens), p.m.valkenburg@uva.nl (P.M. Valkenburg).
}

(APA, 2013), social media addiction still has no status in the DSM-5. While the exclusion of social media addiction from the DSM-5 may give the impression that social media addiction is not a legitimate mental disorder, there is a growing body of evidence suggesting otherwise (Pantic, 2014; Ryan, Chester, Reece, \& Xenos, 2014). Moreover, there is empirical evidence indicating that compulsive social media use is a growing mental health problem, particularly among adolescent smartphone users (Van Rooij \& Schoenmakers, 2013). However, the absence of a clear definition and a measure for social media addiction hampers research on the prevalence of this type of disordered behavior, thereby obstructing vital next steps in the research field of social media addiction. Therefore, the present study aims to develop and validate a new instrument for measuring social media addiction - that is, the Social Media Disorder (SMD) Scale.

Currently, the research field of social media addiction largely lags behind research on game addiction. Whereas research on game addiction has a long history dating back before online games were available (e.g., Shotton, 1989; Soper \& Miller, 1983), the social media addiction field is relatively young, with the first studies appearing after 2010 (for a review, see Ryan et al., 2014). Furthermore, while there are several validated instruments for measuring game addiction (e.g. Griffiths, 2005, Lemmens, Valkenburg, \& Peter, 2009; Lemmens, Valkenburg, \& Gentile, 2015; Van Rooij, Schoenmakers, Van den Eijnden, Vermulst, \& Van de Mheen, 
2010), no validated instruments exist measuring social media addiction. Instead, the field of social media addiction is characterized by an abundance of measurement instruments tapping into particular forms of compulsive social media use, such as Facebook addiction (Ryan et al., 2014), addiction to social network sites (Griffiths, Kuss, \& Demetrovics, 2014), Twitter addiction (Saaid, AlRashid, \& Abdullah, 2014), and microblogging dependence (Wang, Lee, \& Hua, 2015).

The fragmentation in the social media research field, along with the proliferation of measures targeting specific forms of social media addiction, is problematic for two reasons. First, the social media landscape is characterized by rapid changes, whereby existing social media platforms are expanded with new interactive functions or simply replaced by new platforms. Instruments targeting specific forms of social media addiction may thus be outdated easily. Second, existing measures tend to use slightly different criteria for -or operationalization of- social media addiction, thereby hampering the comparability of research data and stimulating further fragmentation of the field. Hence, to accomplish the necessary progress in the field of social media addiction, it is vital to develop and validate a general measure of social media addiction based on a solid set of existing diagnostic criteria.

There is ample ground for the development of a general social media addiction instrument, since social media platforms share many characteristics such as facilitating social interaction, the sharing of ideas, formation and maintenance of relationships and/ or interest groups, and development of one's presence, reputation, and identity (Kietzmann, Hermkens, McCarthy, \& Silvestre, 2011). Moreover, the finding that excessive use of different person-based and group-based social media applications is related to Internet addiction (Kuss \& Griffiths, 2012; Kuss, Van Rooij, Shorter, Griffiths, \& Van de Mheen, 2013; Van den Eijnden, Meerkerk, Vermulst, Spijkerman \& Engels, 2007; Van Rooij et al., 2010) justifies the development of a general social media addiction instrument.

\subsection{Development and validation of the Social Media Disorder (SMD) scale}

The basic theoretical assumption underlying the development of the Social Media Disorder (SMD) scale in the current study is that social media addiction and Internet Gaming Disorder (IGD; APA, 2013) are two forms of the same overarching construct Internet addiction and should therefore be defined by the same set of diagnostic criteria. As stated before, the Internet incorporates a variety of potential activities, and some of these activities, such as gaming and social media use, tend to elicit compulsive tendencies in a subgroup of users. Therefore, the measurement of SMD should correspond with the measurement of both Internet addiction and IGD. Thus, the same set of diagnostic criteria should be used when operationalizing these related concepts.

In recent years, the addiction literature has extensively reflected on the existence of non-substance related or behavioral addictions, such as Internet addiction. In the absence of DSM-criteria for Internet addiction, most instruments were based on the DSM-IV criteria for substance dependence and/or pathological gambling. More specifically, most instruments developed to assess Internet addiction included at least six of the DSM-IV criteria for pathological gambling, namely preoccupation, tolerance, withdrawal, relapse, mood modification, and external consequences (see Van Rooij \& Prause, 2014). These six criteria were also recognized as the core elements of behavioral addictions (Brown, 1993; Griffiths, 1999; Marks, 1990) and used for the development of most game addiction measures (King, Haagsma, Delfabbro, Gradisar, \& Griffiths, 2013).

Based on thorough consideration by a multidisciplinary expert group (see Petry et al., 2014), the APA decided to include three additional criteria when defining the criteria for the DSM-5 diagnosis of IGD, namely deception (e.g., Demetrovics et al., 2012; Gentile et al., 2011), displacement (e.g., Huang, Wang, Qian, Zhong, \& Tao, 2007; Rehbein, Kleimann, \& Mössle, 2010), and conflict (e.g., Lemmens et al., 2009; Young, 1996). Moreover, several authors in the field of IGD refer to relapse as persistence, to mood modification as escape, and to external consequences as problems (Lemmens et al., 2015; Petry et al., 2014).

According to the DSM-5 definition, someone is diagnosed with having IGD if he or she meets five (or more) of the nine criteria for IGD during a period of 12 months. Since SMD and IGD are regarded as two specific forms of the overarching construct Internet addiction, it is reasoned that the nine criteria for IGD, which is the first internet-related disorder included in the DSM, can also be used to define SMD. The development of a SMD scale will thus be based on the DSM-5 diagnostic criteria for IGD and will include the same nine diagnostic criteria.

As suggested before, the development and validation of a theoretically grounded and well-defined instrument to measure SMD is essential in order to prevent the use of a large variety of slightly different measurement instruments that do not allow for clear-cut off points, and may not be applicable to multiple types of social media. Moreover, there is a vital need for utilizing actual clinical criteria in order to differentiate between pathological (i.e. addictive) and highly engaged social media users (Kuss et al., 2013). Thus, the development and validation of an instrument that is using a clear diagnostic cut-off point, as provided by DSM-5, is crucial for the development of this research field because such an instrument offers the opportunity to assess and monitor the prevalence of social media addiction in the population. Since SMD can be expected to be particularly disturbing for the psychosocial development of adolescents (Valkenburg \& Peter, 2011), the SMD scale will be tuned to adolescents.

\subsection{The current study}

The main aim of the present study was to develop and validate a scale to measure Social Media Disorder (SMD). Since SMD and IGD are conceptualized as meeting at least five of the nine DSM-5 criteria for IGD, this study builds on a previous study testing the reliability and validity of a short (9-item) and a long (27-item) scale to measure IGD (Lemmens et al., 2015). Lemmens et al. (2015) showed that the short 9-item scale, with a dichotomous (yes/no) response scale, provided a valid and reliable measure of IGD with good diagnostic accuracy, even in comparison to the long 27-item scale. Because of the important advantages of a short and easy to administer measurement instrument, such as the possibility to incorporate the scale into space-limited surveys, and in agreement with the findings by Lemmens et al. (2015), the ultimate aim of the present study was to develop and validate a short 9-item scale to measure SMD.

Our starting point was the development of a 27-item SMD scale, consisting of three items for each of the nine DSM-5 criteria (see Appendix A). After testing the factor structure and factor loadings of this 27-item scale, the nine items with the highest factor loading per criterion were selected to constitute the short 9-item scale. Next, the psychometric properties of the short SMD scale were tested, and compared with some psychometric properties of the 27-item SMD scale. More specifically, we examined (1) the factor 
structure and internal consistency, (2) construct validity, as indicated by convergent validity, (3) criterion validity, (4) test-retest reliability, and (5) sensitivity and specificity of the short SMD scale. These psychometric properties were tested across three different samples of Dutch adolescents to establish population cross-validation. Finally, we established the prevalence of SMD in the current three samples, and tested for group differences in gender, age, and frequency of daily social media use between disordered and non-disordered adolescents.

Construct validity is defined as the extent to which the scale measured the intended construct. Construct validity of the SMD scale was established by testing the strength of the relationships between scores on the SMD scale and constructs to which it should theoretically be related. An important aspect of construct validity is convergent validity, referring to the relation between the SMD scale and comparable constructs. In this study convergent validity was tested by relating scores on the SMD scale to Compulsive Internet Use, as measured by the Compulsive Internet Use Scale (CIUS; Meerkerk et al., 2009), and to self-declared social media addiction. In case of good convergent validity, we expect to find strong correlations between scores on the SMD scale and scores on the CIUS and on self-declared social media addiction.

Criterion validity is defined as the extent to which a measure is related to an outcome. Criterion validity of the SMD scale was examined by testing the relationship between scores on the SMD scale and several psychosocial constructs that have previously been related to compulsive Internet use and (specific forms of) compulsive social media use: self-esteem (Mehdizadeh, 2010; Van Rooij et al., 2015), depression (Caplan, 2007; Hong, Huang, Lin, \& Chiu, 2014; Koc \& Gulyagci, 2013; Yen, Ko, Yen, Wu, \& Yang, 2007), loneliness (Caplan, 2007; Odaci \& Kalkan, 2010; Van Rooij et al., 2015), attention deficit (Dalbudak \& Evren, 2014; Van Rooij et al., 2015; Weinstein \& Lejoyeux, 2010; Yen et al., 2007), and impulsivity (Dalbudak \& Evren, 2014; Wu, Cheung, Ku, \& Hung, 2013). We expect to find weak to moderate correlations between scores on the SMD scale and these psychosocial constructs. Finally, in line with previous studies on the relationship between compulsive Internet use and daily time online (Meerkerk et al., 2009), and between IGD and time spent gaming (Lemmens et al., 2015; Van Rooij et al., 2012), we expect to find moderate associations between the SMD scale and frequency of daily social media use.

\section{Method}

\subsection{Sample and procedure}

From November 2014 through April 2015, three online surveys were conducted among a total of 2198 Dutch adolescents, who were all recruited through Marketing Science Institute (MSI), an international market research company located in the Netherlands. In November 2014, the first online questionnaire was distributed among 724 teenagers ( $54 \%$ girls) aged $10-17(M=14.36, S D=2.11)$. Respondents received credit points for participating that could later be redeemed for prizes. A second online survey was distributed two months later among a sample of 873 adolescents, aged 10-17, ( $M=14.28, S D=2.15,48 \%$ girls $)$, of whom 238 had also completed the first questionnaire. Finally, a third online survey was conducted among a new sample of 601 adolescents aged 10-17 $(M=14.05$, $S D=2.18,50 \%$ girls).

\subsection{Measures}

The first online survey included the 27-item SMD scale, as well as validity measures; that is, Compulsive Internet Use, Self-declared
Social Media Addiction, Self-esteem, Depression, Attention Deficit, Impulsivity, and the use of several social media applications. The second online survey contained the short 9-item SMD scale and also measured Depression, Attention Deficit, Impulsivity, and the additional variable Loneliness, in order to further test construct validity. The third survey contained the 27 -item SMD scale and a wider range of items regarding smartphone usage than the first survey (e.g., WhatsApp).

\subsubsection{Social Media Disorder}

The SMD scale consisted of 27 items (see Appendix A). Three items were created for each of the previously identified nine criteria: Preoccupation, Tolerance, Withdrawal, Displacement, Escape, Problems, Deception, Displacement, and Conflict.

\subsubsection{Compulsive Internet Use}

Compulsive Internet use was assessed in the first sample using the 14-item Compulsive Internet Use Scale (Meerkerk et al., 2009). Example items are: 'How often do you feel restless, frustrated, or irritated when you cannot use the Internet?' and 'How often do you find it difficult to stop using the Internet when you are online?' Items were assessed on a 5-point scale, ranging from (1) never to (5) very often. Cronbach's alpha was $0.93(M=2.28, S D=0.78)$.

\subsubsection{Self-declared Social Media Addiction}

Respondents were asked: "To what extent do you feel addicted to social media?" Answers to this question were given on a 5-point scale ranging from (1) not at all addicted to (5) strongly addicted.

\subsubsection{Self-esteem}

The degree of self-esteem was measured using the six-item selfesteem scale (Rosenberg, Schooler, \& Schoenbach, 1989). This measure implies feelings of self-acceptance, self-respect and generally positive self-evaluation. Sample items are: "I am able to do things at least as well as other people" and "I feel that I don't have much to be proud of" (reverse coded). Response categories ranged from 1 (totally disagree) to 5 (totally agree). The items were averaged to create the scale scores. Cronbach's alpha for this scale was $0.84(M=3.78, S D=0.73)$.

\subsubsection{Depression}

Depression was assessed using the 6-item Kutcher Adolescent Depression Scale (LeBlanc, Almudevar, Brooks, \& Kutcher, 2002). Respondents were asked whether items were applicable to them on a 5-point scale, ranging from never (1) to very often (5). Example items are "I feel there is little hope for the future" and "I feel unhappy and depressed". Items were averaged to create scale scores. Cronbach's alpha was $0.86(M=2.58, S D=0.84)$ in the first sample, and $0.87(M=2.51, S D=0.85)$ in the second sample.

\subsubsection{Attention deficit}

The extent to which respondents displayed symptoms of Attention Deficit was assessed by adapting nine items from the DSM-IV checklist for ADHD that focused on attention deficit, or inattention (APA, 2000). As proposed by Kessler et al. (2005), respondents were asked to indicate how often nine situations were applicable to them on a 5-point scale ranging from never (1) to very often (5). Example items are "I am easily distracted" and "I have difficulties organizing tasks". Items were averaged to create scale scores. Cronbach's alpha was 0.89 in the first sample $(M=2.59$, $S D=0.74)$. In the second sample, Cronbach's alpha was 0.88 $(M=2.58, S D=0.71)$.

\subsubsection{Impulsivity}

The extent to which respondents displayed symptoms of 
impulsivity was assessed using six items adapted from the DSM-IV checklist for ADHD that focused on impulsivity (APA, 2000). Example items are "I have difficulty awaiting my turn" and "I interrupt or intrude on others". Respondents were asked to indicate how often these six situations were applicable to them on a 5-point scale ranging from never (1) to very often (5). Items were averaged to create scale scores. Cronbach's alpha was $0.84(M=2.16$, $S D=0.67)$ in the first sample. In the second sample, Cronbach's alpha was $0.80(M=2.24, S D=0.72)$.

\subsubsection{Loneliness}

Feelings of loneliness were assessed with the 10-item Loneliness Scale developed by Russell, Peplau, and Cutrona (1980); this scale contained 5 positive and 5 negative items. Examples of items are "I feel completely alone", "I have nobody to talk to", and "there are people who really understand me." Negative items were recoded before summing the 10 items into a scale. The internal consistency of the scale was high; Cronbach's alpha was $0.90(M=2.18, S D=0.99)$.

\subsubsection{Frequency of daily social media use}

The frequency of daily social media use was measured by presenting a list of the fifteen most popular social media. Respondent were asked to indicate how often they used these social media on a daily basis. Answer options were: (0) never (1) less than once a day (2) 1-2 times (3) 3-5 times (4) 6-10 times (5) 11-20 times (6) 21-40 times (7) more than 40 times a day. Finally, we also asked for each type of social media platform or app how often respondents posted something, using the same 7-point scale.

\subsection{Strategy of analyses}

First of all, we tested whether the 27 items of the SMD scale, consisting of three items for each of the nine DSM-5 criteria, can be accounted for by one higher-order factor: social media disorder). This factor structure was tested in the two independent samples, the first and third one. We used structural equation modeling (SEM) with weighted least squares estimators to test these secondorder factor models using CFA in MPlus (Asparouhov \& Muthén, 2009). Although maximum likelihood is the most common estimation method in CFA, this method assumes that observed variables are continuous and normally distributed in the population (Lubke \& Muthén, 2004). Because this assumption was not met with our skewed distribution of SMD and ordinal levels of measurement, a weighted least squares approach was applied to our data, allowing any combination of dichotomous, ordered categorical, or continuous observed variables (Flora \& Curran, 2004). Although researchers sometimes correlate error terms on the basis of theoretically overlapping indicators in an effort to improve model fit, this should be avoided if possible, since it means that there is some other issue that is not specified within the model that is causing the covariation (Hooper, Coughlan, \& Mullen, 2008). Therefore, the error terms associated with each observed item are uncorrelated (Byrne, 2001).

The goodness of fit was evaluated using the chi-square value, the Comparative Fit Index (CFI), the Root Mean Square Error of Approximation (RMSEA), and its 90\% confidence interval (CI). Particularly when dealing with large samples, the chi square test is not a good indicator of fit, and the CFI and RMSEA indices are considered informative fit criteria in SEM (Byrne, 2001). A good fit is expressed by a CFI greater than 0.95 and a RMSEA value less than 0.08 (Byrne, 2001; Hu \& Bentler, 1999; Yu \& Muthén, 2002). In addition, the internal consistency of the 27-item scale was calculated by means of Cronbach's alpha.
Next, a short 9-item version of the SMD scale was developed that encompasses all DSM-5 criteria by selecting the highest loading items from each criterion. The standardized item-loadings from sample 1 were used to select a set of nine items with the highest overall loadings from each of the nine first-order factors. This short version of the scale was then tested as a first-order structural model using Mean- and Variance-adjusted Weighted Least Square (WLSMV) estimators in Mplus. Internal consistency of the 9-item scale was calculated in all three samples by means of Cronbach's alpha.

We also investigated the population cross-validity of the onedimensional structure of the short 9-item scale. More specifically, we tested whether the hypothesized one-dimensional structure of the short SMD scale, which was found in the first sample, was also found in the second and third sample. Population cross-validity is satisfactory when the results found in one sample of a population can also be found in another independent sample drawn from the same population (e.g., Raju, Bilgic, Edwards, \& Fleer, 1997).

After testing the factor structure and internal consistency of the long 27-item and short 9-item SMD scale (first aim), we examined the construct validity of these scales (second aim). More specifically, we assessed convergent validity, which can be established if two similar constructs correspond with one another. To assess convergent validity, respondents' sum scores on the SMD scale were correlated with compulsive Internet use, and self-declared social media addiction. Next, we determined criterion validity (third aim), that is, the extent to which a measure is related to an outcome that it theoretically should be related to. We assessed criterion validity by correlating the scores on the SMD scale with self-esteem, depression, loneliness, attention deficit, and impulsivity. The following criteria were used to classify magnitude of correlations: small, $r=.1-.29$; medium, $r=.3-.49$; large, $r=.5-1.0$ (Cohen, 1960).

The fourth aim was to calculate the test-retest reliability of the short 9-item SMD scale. We investigated the test-retest reliability by computing Pearson correlations between scores on the short SMD scales among the 238 adolescents who participated in the first and second online survey. In addition, the intra-class correlation coefficient (ICC) was established, using a two factor mixed effects model and type consistency (McGraw \& Wong, 1996). The fifth aim was to determine the sensitivity and specificity of the nine items of the short SMD scale. However, before doing so, we examined the prevalence of SMD in the three samples as indicated by the five-ormore cut-off point of the short SMD scale, and we tested for group differences in gender, age, and frequency of daily social media use between disordered and non-disordered adolescents. Next, sensitivity was demonstrated by the proportion of disordered social media users who answered 'yes' on an indicator of SMD, whereas specificity was indicated by the proportion of non-disordered users who reported 'no' on an indicator of SMD.

\section{Results}

\subsection{Social media use}

The reported results on social media use are derived from the combined samples 1 and $3(N=1325)$ unless otherwise specified. A small group (Sample 1: 6.6\%, $n=88$; Sample 2: $10,3 \%, n=90$ ) reported not using any form of social media and was excluded from analyses. Out of all 1237 social media users, 92.2\% $(n=1140)$ reported owning a smartphone and using it for social media. The most popular social media platforms and apps are displayed in Table 1. 
Table 1

The most popular social media $(\mathrm{N}=1325)$.

\begin{tabular}{|c|c|c|c|c|}
\hline & Total users & Users on smartphone ${ }^{a}$ & Daily posts ( $\geq 1$ post) & Daily posts ( $>10$ posts) \\
\hline Facebook & $83 \%$ & $68 \%$ & $46 \%$ & $1 \%$ \\
\hline WhatsApp ${ }^{\mathrm{b}}$ & $82 \%$ & $82 \%$ & $82 \%$ & $32 \%$ \\
\hline Instagram & $54 \%$ & $51 \%$ & $41 \%$ & $1 \%$ \\
\hline YouTube & $53 \%$ & $43 \%$ & $33 \%$ & $1 \%$ \\
\hline Twitter & $34 \%$ & $26 \%$ & $19 \%$ & $2 \%$ \\
\hline
\end{tabular}

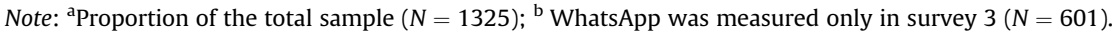

\subsection{The dimensional structure of the SMD scale}

The 27-item scale was included in the first sample $(N=724)$, $M=5.65, S D=5.5$ and in the third sample $(N=601), M=5.65$, $S D=6.17$. For analyses, all yes-answers were summed (range $0-27$ ). The dimensional structure of the 27-item SMD scale (3 items per criterion) was tested using a second-order factor model. This resulted in an acceptable model fit, $\chi^{2}(288, n=724)=672.424$, $p<0.001, \mathrm{CFI}=0.963$, RMSEA $=0.043$ (90\% CI: 0.039-0.047) in the first sample. Similarly, in the third sample $(n=601)$, the same model also showed an acceptable model fit, $\chi^{2}$ (288, $n=601)=570.681, p<0.001, \mathrm{CFI}=0.973$, RMSEA $=0.040(90 \% \mathrm{CI}$ : $0.036-0.045)$. Moreover, the 27-item SMD scale showed good internal consistency with a Cronbach's alpha of 0.90 in the first sample and 0.92 in the third sample. Table 2 shows the factor loadings and percentages of affirmative answers for all 27 items in samples 1 and 3 .

\subsection{Constructing a short SMD scale and testing population cross- validity}

In order to facilitate incorporation of the SMD scale into spacelimited surveys, and assess the prevalence of SMD among adolescents, an important aim of this study was to investigate whether a

Table 2

Affirmative answers and confirmatory factor loadings of SMD items.

\begin{tabular}{|c|c|c|c|c|c|}
\hline \multirow[t]{2}{*}{ \# } & \multirow[t]{2}{*}{ Criterion } & \multicolumn{2}{|c|}{ Sample $1(n=724)$} & \multicolumn{2}{|c|}{ Sample $3(n=601)$} \\
\hline & & $\%$ yes & Loadings $(\beta)$ & $\%$ yes & Loadings $(\beta)$ \\
\hline 1 & Preoccupation 1 & 44 & 0.686 & 44 & 0.676 \\
\hline 2 & Preoccupation2 & 12 & 0.784 & 13 & 0.860 \\
\hline 3 & Preoccupation3 & 30 & 0.554 & 32 & 0.631 \\
\hline 4 & Tolerance 1 & 39 & 0.713 & 35 & 0.829 \\
\hline 5 & Tolerance2 & 32 & 0.742 & 30 & 0.833 \\
\hline 6 & Tolerance3 & 09 & 0.902 & 10 & 0.938 \\
\hline 7 & Withdrawal1 & 22 & 0.781 & 24 & 0.833 \\
\hline 8 & Withdrawal2 & 16 & 0.886 & 21 & 0.894 \\
\hline 9 & Withdrawal3 & 13 & 0.946 & 14 & 0.963 \\
\hline 10 & Persistence1 & 18 & 0.854 & 18 & 0.876 \\
\hline 11 & Persistence2 & 16 & 0.975 & 17 & 0.896 \\
\hline 12 & Persistence3 & 16 & 0.908 & 15 & 0.926 \\
\hline 13 & Displacement1 & 29 & 0.773 & 33 & 0.769 \\
\hline 14 & Displacement 2 & 18 & 0.919 & 22 & 0.844 \\
\hline 15 & Displacement 3 & 13 & 0.903 & 16 & 0.873 \\
\hline 16 & Problems1 & 27 & 0.647 & 30 & 0.684 \\
\hline 17 & Problems2 & 35 & 0.601 & 34 & 0.666 \\
\hline 18 & Problems3 & 09 & 0.889 & 09 & 0.858 \\
\hline 19 & Deception1 & 14 & 0.814 & 16 & 0.928 \\
\hline 20 & Deception2 & 13 & 0.760 & 13 & 0.947 \\
\hline 21 & Deception3 & 20 & 0.760 & 20 & 0.936 \\
\hline 22 & Escape1 & 28 & 0.919 & 27 & 0.905 \\
\hline 23 & Escape2 & 23 & 0.954 & 24 & 0.819 \\
\hline 24 & Escape3 & 20 & 0.965 & 19 & 0.834 \\
\hline 25 & Conflict1 & 08 & 0.814 & 11 & 0.874 \\
\hline 26 & Conflict2 & 08 & 0.877 & 11 & 0.825 \\
\hline 27 & Conflict3 & 06 & 0.842 & 05 & 0.809 \\
\hline
\end{tabular}

Note: Item descriptions are found in Appendix A. 9-item model would provide an equal or even better description of the data. In sample 1, the unconstrained first-order structural 9item model using Mean- and Variance-adjusted Weighted Least Square (WLSMV) estimators yielded a good fit, $\chi^{2}$ (27, $n=724)=24.846, p=0.58, \mathrm{CFI}=1.000$, RMSEA $=0.000(90 \% \mathrm{CI}$ : $0.000-0.026$ ). This short SMD scale was strongly correlated with the 27-item SMD scale $(r=0.89, p<0.001)$ and showed good reliability with a Cronbach's alpha of $0.81(M=1.22, S D=1.87)$. Items for the short 9-item SMD scale are displayed in Table 3. The total time to complete the short 9-item SMD scale was about $45 \mathrm{~s}$, compared to about 2 min and $15 \mathrm{~s}$ for completing the 27 -item scale.

In a next step, we examined the population cross-validity by testing whether the one-dimensional structure of the short SMD scale that was found in the first sample, could also be found in the second and third sample. Again, the unconstrained first-order structural 9-item model yielded a good fit, $\chi^{2}$ (27, $n=873)=62.852, p=0.001, \mathrm{CFI}=0.997, \mathrm{RMSEA}=0.041(90 \% \mathrm{CI}$ : 0.028-0.055). Furthermore, the 9-item scale showed adequate reliability with a Cronbach's alpha of $0.76(M=1.94, S D=2.11)$. Finally, in sample 3, the unconstrained first-order structural 9-item model also yielded a good fit, $\chi^{2}(27, n=601) 54.129, p=0.002$, $\mathrm{CFI}=0.989$, RMSEA $=0.041$ (90\% CI: 0.025-0.057). In this sample, the 9 -item scale also showed a strong correlation with the 27-item scale $(r=0.94, p<0.001)$ and showed good reliability with a Cronbach's alpha of $0.82(M=1.52, S D=2.11)$.

\subsection{Convergent and criterion validity of the SMD scales}

In order to establish the convergent validity, respondents' mean scores on the long and short SMD scales were correlated with compulsive Internet use and self-declared social media addiction. Next, to assess the criterion validity, the SMD scales were correlated with dissimilar but related constructs, i.e. depression, self-esteem, loneliness, attention deficit, impulsivity, and frequency of daily social media use. As Table 4 shows, all correlations were significant at least at $p<0.001$ in the expected directions. The long (27-item) and short (9-item) versions of the SMD scale both showed large positive correlations with compulsive Internet use $(r>0.50)$ and medium to large correlations with self-declared social media addiction, ( $r>0.48$ ), indicating satisfactory convergent validity.

With regard to criterion validity, the long and short SMD scales showed medium positive correlations with depression, attention deficit, and frequency of daily social media use and posts, and weak to moderate positive associations with loneliness and impulsivity (see Table 4). Finally, a small negative correlation with self-esteem was found. The correlations between the SMD scales and these related constructs indicated good criterion validity. Overall, the strength of the correlations between the SMD scales and these similar and related constructs was somewhat lower for the 9-item scale than for the 27-item scale, but the 9-item scale still demonstrated satisfactory convergent and criterion validity. 
Table 3

The 9-item SMD scale.

\begin{tabular}{ll}
\hline Criterion & During the past year, have you ... \\
\hline Preoccupation & $\ldots$ regularly found that you can't think of anything else but the moment that you will be able to use social media again? \\
Tolerance & $\ldots$ regularly felt dissatisfied because you wanted to spend more time on social media? \\
Withdrawal & $\ldots$ often felt bad when you could not use social media? \\
Persistence & $\ldots$ tried to spend less time on social media, but failed? \\
Displacement & $\ldots$ regularly neglected other activities (e.g. hobbies, sport) because you wanted to use social media? \\
Problem & $\ldots$ regularly had arguments with others because of your social media use? \\
Deception & $\ldots$ regularly lied to your parents or friends about the amount of time you spend on social media? \\
Escape & $\ldots$ often used social media to escape from negative feelings? \\
Conflict & $\ldots$ had serious conflict with your parents, brother(s) or sister(s) because of your social media use? \\
\hline
\end{tabular}

Table 4

Correlations Between the 9- and 27-item SMD scales and Validation Constructs.

\begin{tabular}{|c|c|c|c|c|c|}
\hline & \multicolumn{2}{|c|}{ Sample $1(\mathrm{~N}=724)$} & \multirow{2}{*}{$\frac{\text { Sample } 2(\mathrm{~N}=873)}{\text { SMD } 9}$} & \multicolumn{2}{|c|}{ Sample $3(\mathrm{~N}=601)$} \\
\hline & SMD 27 & SMD 9 & & SMD 27 & SMD 9 \\
\hline CIUS & 0.57 & 0.51 & - & - & - \\
\hline Self-declared SMD & 0.60 & 0.48 & & & \\
\hline Self-Esteem & -0.19 & -0.19 & - & - & - \\
\hline Depression & 0.37 & 0.29 & 0.29 & - & - \\
\hline Loneliness & - & - & 0.24 & - & - \\
\hline Attention Deficit & 0.36 & 0.33 & 0.26 & - & - \\
\hline Impulsivity & 0.30 & 0.30 & 0.27 & - & - \\
\hline Frequency Daily Use & 0.35 & 0.25 & - & 0.25 & 0.20 \\
\hline Frequency Daily Posts & 0.34 & 0.27 & - & 0.28 & 0.24 \\
\hline
\end{tabular}

Note: All correlations are significant at $p<0.001$.

\subsection{Test-retest reliability of the 9-item SMD scale}

Test-retest reliability of the 9-item short SMD scale was assessed among the 238 adolescents who participated in both the first and the second online survey (with an interval of 2 months between these two surveys). A moderate degree of reliability was found between the first and second SMD scales. The Pearson correlation between both scales was $0.50, \mathrm{p}<0.001$. The averaged measure ICC using an absolute agreement definition, was.663 (95\% CI:.565-.739), and the mean variation between the measures of SMD was 0.47 . An averaged measure ICC of 0.60 or higher indicates satisfactory stability (Landis \& Koch, 1977).

\subsection{Prevalence of Social Media Disorder}

The 9-item SMD scale was used to assess the prevalence of disordered social media use among teenagers. In accordance with the cut-off point for IGD in the DSM-5, at least five or more (out of nine) criteria must be met for a formal diagnosis of 'disordered social media user'. Among the first sample $(N=724)$, we found that 53 teenagers met five or more of the criteria (7.3\%). In the second sample $(N=873), 101$ adolescents $(11.6 \%)$ met the cut-off point for disordered use of social media. In the third sample $(N=601), 62$ teenagers (10.3\%) could be viewed as disordered social media users.

Also, we examined whether disordered social media users differed from non-disordered users with regard to gender, age, and frequency of daily social media use. Chi-square tests for the first sample indicated that there were more disordered boys ( $n=34$, $10.2 \%)$ than disordered girls $(n=19,4.9 \%), \chi^{2}(1,724)=7.471$, $p=0.006$. The second and third sample, however, did not replicate this gender difference: in the second sample, the number of boys among disordered social media users $(n=45,9.9 \%)$ did not differ from the number of disordered girls $(n=56,13.3 \%), \chi^{2}(1$, $873)=2.462, p=0.117$. Similarly, in the third sample no differences between boys $(n=26,8.7 \%)$ and girls $(n=36,12.0 \%), \chi^{2}(1$, $601)=1.762, p=0.148$, were found.
With regard to age, no differences were found between disordered and non-disordered users (sample $1, t(1,722)=1.40$, $p=0.16$; sample $2, t(1,781)=0.60, p=0.55$; sample $3, t$ $(1,599)=-0.30, p=0.77)$. Table 5 illustrates the differences in use of specific social media applications between disordered and nondisordered social media users. In the first sample, all social media are used more often among disordered users. In the third sample, significant differences were only demonstrated for active use of Facebook, Instagram, and Whatsapp.

\subsection{Sensitivity and specificity of the 9-item SMD scale}

Finally, each of the nine indicators of the SMD scale was examined for their sensitivity and specificity. Sensitivity of the short scale items was demonstrated by the proportion of disordered social media users from each sample $(n ' s=53,101,63)$ who answered positively on an item, whereas specificity was indicated by the proportion of negative responses on a scale item by nondisordered gamers from each sample. Ideally, both sensitivity and specificity of an item should be high in order to discriminate false positives and false negatives (Glaros \& Kline, 1988). As Table 6 shows, the nine items show adequate sensitivity and high specificity. The diagnostic accuracy, as indicated by the proportion of all true positives (indicating sensitivity) and true negatives (indicating specificity), was highly comparable across samples. The sensitivity of Problems and Conflict were the lowest of all items across samples, indicating that between $47 \%$ and $62 \%$ of all disordered social media users had experienced serious problems as a result of their compulsive social media use, and that between $50 \%$ and $61 \%$ of the disordered users had experienced conflicts with friends, family or partners because of their social media use. Conversely, the specificity of Problems and Conflict was high across samples (ranging between 0.92 and 0.97 ) indicating that between $3 \%$ and $8 \%$ of the social media users who had experienced problems and conflicts were not among the disordered gamers. 
Table 5

Mean frequency of daily social media use ${ }^{\mathrm{a}}$ of disordered and non-disordered users.

\begin{tabular}{|c|c|c|c|c|}
\hline & \multicolumn{2}{|c|}{ Sample $1(N=724)$} & \multicolumn{2}{|c|}{ Sample $3(N=601)$} \\
\hline & Non-disordered & Disordered & Non-disordered & Disordered \\
\hline Facebook use & $3.20(1.44)$ & $3.70(1.53)^{*}$ & $3.26(1.33)$ & $3.57(1.64)$ \\
\hline Facebook posts & $1.43(0.67)$ & $2.13(1.15)^{*}$ & $1.64(0.90)$ & $2.08(0.99)^{*}$ \\
\hline FB messenger use & - & - & $2.44(1.18)$ & $3.03(1.55)^{*}$ \\
\hline FB messenger posts & - & - & $1.88(1.08)$ & $2.60(1.42)^{*}$ \\
\hline Instagram use & $3.44(1.52)$ & $4.06(1.63)^{*}$ & $3.54(1.37)$ & $3.78(1.71)$ \\
\hline Instagram posts & $1.60(0.84)$ & $2.31(1.53)^{*}$ & $1.75(0.91)$ & $2.22(0.87)^{*}$ \\
\hline YouTube use & $1.21(0.70)$ & $1.57(1.07)^{*}$ & $3.30(1.33)$ & $3.37(1.33)$ \\
\hline YouTube posts & $1.21(0.69)$ & $1.57(1.07)^{*}$ & $1.58(0.99)$ & $1.86(1.04)$ \\
\hline Twitter use & $1.60(1.17)$ & $2.70(2.05)^{*}$ & $2.41(1.38)$ & $2.88(1,80)$ \\
\hline Twitter posts & $1.59(1.17)$ & $2.70(2.05)^{*}$ & $1.73(0.99)$ & $1.88(1.00)$ \\
\hline WhatsApp posts & - & - & $4.13(1.58)$ & $5.08(1.71)^{*}$ \\
\hline
\end{tabular}

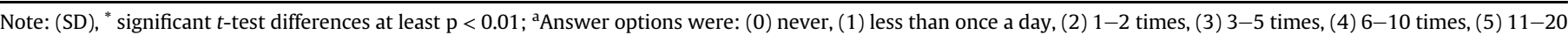
times, (6) 21-40 times, and (7) more than 40 times a day.

Table 6

Sensitivity and specificity of the nine criteria for Social Media Disorder.

\begin{tabular}{|c|c|c|c|}
\hline & Disordered users sample $1(n=53)$ & Disordered users sample $2(n=101)$ & Disordered users sample $3(n=62)$ \\
\hline & Sens - Spec & Sens - Spec & Sens - Spec \\
\hline Preoccupation & $0.74-0.92$ & $0.79-0.87$ & $0.77-0.94$ \\
\hline Tolerance & $0.74-0.97$ & $0.66-0.93$ & $0.66-0.96$ \\
\hline Withdrawal & $0.87-0.94$ & $0.78-0.85$ & $0.81-0.93$ \\
\hline Persistence & $0.81-0.88$ & $0.69-0.77$ & $0.69-0.83$ \\
\hline Displacement & $0.62-0.97$ & $0.76-0.83$ & $0.73-0.84$ \\
\hline Problems & $0.62-0.92$ & $0.55-0.93$ & $0.47-0.95$ \\
\hline Deception & $0.77-0.91$ & $0.66-0.89$ & $0.71-0.90$ \\
\hline Escape & $0.79-0.82$ & $0.66-0.83$ & $0.71-0.82$ \\
\hline Conflict & $0.59-0.97$ & $0.50-0.95$ & $0.61-0.94$ \\
\hline
\end{tabular}

\section{Discussion}

There is a growing body of evidence suggesting that social media disorder (i.e. addiction) is an emerging mental problem, particularly among adolescents (Pantic, 2014; Ryan et al., 2014). However, the absence of a measurement tool for SMD hampers further development of the research field. Particularly, there is a strong need for an assessment instrument that can distinguish between disordered (i.e. addictive) and highly engaged nondisordered social media users. Therefore, the present study, consisting of three online surveys among adolescents aged 10 to 17 , aimed to test the reliability and validity of a short and easy to administer SMD Scale that contains a clear diagnostic cut-off point.

In the absence of specific diagnostic criteria for SMD, the development of our measurement tool was based on the assumption that SMD and IGD are two forms of the same overarching construct Internet Addiction, and should thus be defined by the same set of diagnostic criteria. Therefore, the development of the SMD scale was based on the nine DSM-5 criteria for IGD (APA, 2013). First, a 27-item dichotomous scale was developed assessing the nine DSM-5 criteria, i.e. preoccupation, tolerance, withdrawal, persistence, escape, problems, deception, displacement, and conflict, with three items per criterion. Next, we examined whether a short 9-item scale, consisting of the nine items with the highest factor loading per criterion, would provide an equally valid and reliable measurement tool.

This study generated evidence that the 9-item scale is a psychometrically sound and valid instrument to measure SMD, and just as valid as the 27 -item version. Confirmatory factor analysis showed good model fits, indicating solid structural validity. The 9item scale also showed appropriate internal consistency, sufficient test-retest reliability, and good convergent and criterion validity.
Moreover, the nine items generally showed adequate sensitivity and good specificity. The prevalence of SMD, determined on basis of the diagnostic cut-off point of the 9-item scale, ranged from $7.3 \%$ to $11.6 \%$ in the 3 online samples.

Convergent validity was determined by the strength of correlations between SMD and similar constructs. As expected, correlations between scores on the SMD scales and scores on the Compulsive Internet Use Scale (CIUS) were strong. Also, the SMD scales showed strong correlations with self-reported social media addiction, although the strength of this correlation was somewhat lower for the 9-item scale than for the 27 -item scale. The strength of the association between the 9-item scale and self-declared social media addiction, however, is substantial and similar to the strength of the previously found association between scores on the CIUS and self-reported Internet addiction (Meerkerk et al., 2009).

Criterion validity was determined on basis of the strength of correlations with psychosocial constructs that were previously related to compulsive Internet use and/or social media use. In line with our expectations, the SMD scales showed moderate relationships in the expected direction with depression, attention deficit and frequency of daily social media use, weak to moderate associations with loneliness and impulsivity. However, only a weak negative association was found with self-esteem.

The relatively stronger associations found for depression and attention deficit coincide with findings of a recent study indicating that depressive mood and hyperactivity-inattention are more strongly related to SMD than to IGD (Van Rooij et al., 2015). The relatively strong link between SMD and attention deficit corroborates the public concern that the use of social media, particularly when used via smartphones (e.g., Whatsapp), is distracting adolescents' attention from their everyday activities and obligations.

A recent review indeed suggests that higher levels of media 
multitasking, i.e. the use of media while engaging in non-media activities, such as completing homework and engaging in face-toface interactions, is related to deficits in cognitive control, in particular to the ability to sustain attention (Van der Schuur, Baumgartner, Sumter, \& Valkenburg, 2015). The relatively high correlation between SMD and attention deficit thus provides some evidence for the scattered attention hypothesis (e.g., Ophira, Nass, \& Wagner, 2009) which states that when people frequently engage in media multitasking, they become accustomed to constant switching between activities and eventually lose their ability to focus on a single activity (Van der Schuur et al., 2015; Wallis, 2006, 2010). However, because of the cross-sectional nature of the present findings, no causal inferences can be made. Future longitudinal and experimental research is warranted to establish causality between SMD and attention deficit in adolescents.

Most of the nine items of the short SMD scale showed good sensitivity and specificity. The items measuring Problems and Conflict, however, showed a lower sensitivity in comparison to the other items of the SMD scale, as well as in comparison to Problems and Conflict items of the IGD-scale (Lemmens et al., 2015). Experiencing conflict with others about the time spent on social media use may have less external validity than conflicts about time spent gaming. Social media use is more easily stopped or combined with other activities, thereby causing fewer problems as a result of compulsive social media use, in comparison to compulsive gaming. Also, having to quit gaming may be experienced as more frustrating by disordered adolescents than having to quit social media use. Consequently, IGD may induce more conflict and arguing with family members than SMD. Previous research indeed showed that disordered gamers display more physical aggression (Lemmens, Valkenburg, \& Peter, 2011) than non-disordered gamers. Future research should address the aptness of the nine DSM-5 criteria for measuring SMD, and examine whether Problems and Conflict are indeed core features of SMD, as was assumed in the present study.

The findings of the third survey suggest that some types of social media use may elicit a higher risk than others, and that disordered users differ from non-disordered users particularly in the number of posts that they place on Facebook, Instagram and Whatsapp. However, these results are somewhat inconsistent with the findings of the first survey suggesting that both passive and active use of social media is related to SMD. Future research should address the strength of the relationships between different types of social media use and SMD in more detail.

Some limitations of the present research warrant discussion. First, the nine DSM-5 criteria defined for IGD were translated to SMD. It should be noted, however, that these nine criteria for IGD are still subject to discussion (e.g. Griffiths et al., 2015; KardefeltWinther et al., 2014). Consequently, using the same nine DSM-5 criteria of IGD to measure SMD may yield similar conceptual debates. For instance, the notion that the criterion of Deception, i.e. lying about the time spend on social media, is socially or culturally subjective and also depend on the people close to the gamer (Kardefelt-Winther et al., 2014), also applies to the current conceptualization of social media disorder. In addition, some of the proposed IGD criteria may be less relevant in the context of social media use. As suggested earlier, Conflict and Problems may be less appropriate criteria to measure SMD, as compared to IGD, and thus strongly require further investigation.

Despite these conceptual shortcomings, we followed the pragmatic approach of developing and validating this short and easy to administer tool to measure SMD, which enables the investigation of trends and developments in the prevalence of SMD during this period of rapid changes in the social media landscape. This study, however, is regarded a first research step, and an important next step would be to investigate the correctness of the nine DSM-5 criteria as the core features of SMD, as well as to test whether the items covered in the short SMD scale indeed are the most suitable ones for diagnosing SMD in both clinical and non-clinical samples. It would be interesting, for instance, to test the extent to which selfdeclared social media addicts identify with the items of both the short 9-item and the long 27-item SMD scale to gain more insight into the actual significance of the nine DSM-5 criteria for determining SMD. After these research steps have been taken, this instrument will facilitate the investigation of psychological processes (motivational, affective, cognitive, interpersonal, and social) sustaining the dysfunctional involvement in social media use (Billieux, Schimmenti, Khazaal, Maurage, \& Heeren, 2015; Dudley, Kuyken, \& Padesky, 2011), and will thereby contribute substantially to understanding Social Media Disorder.

\section{Appendix A}

27 items for the Social Media Disorder Scale.

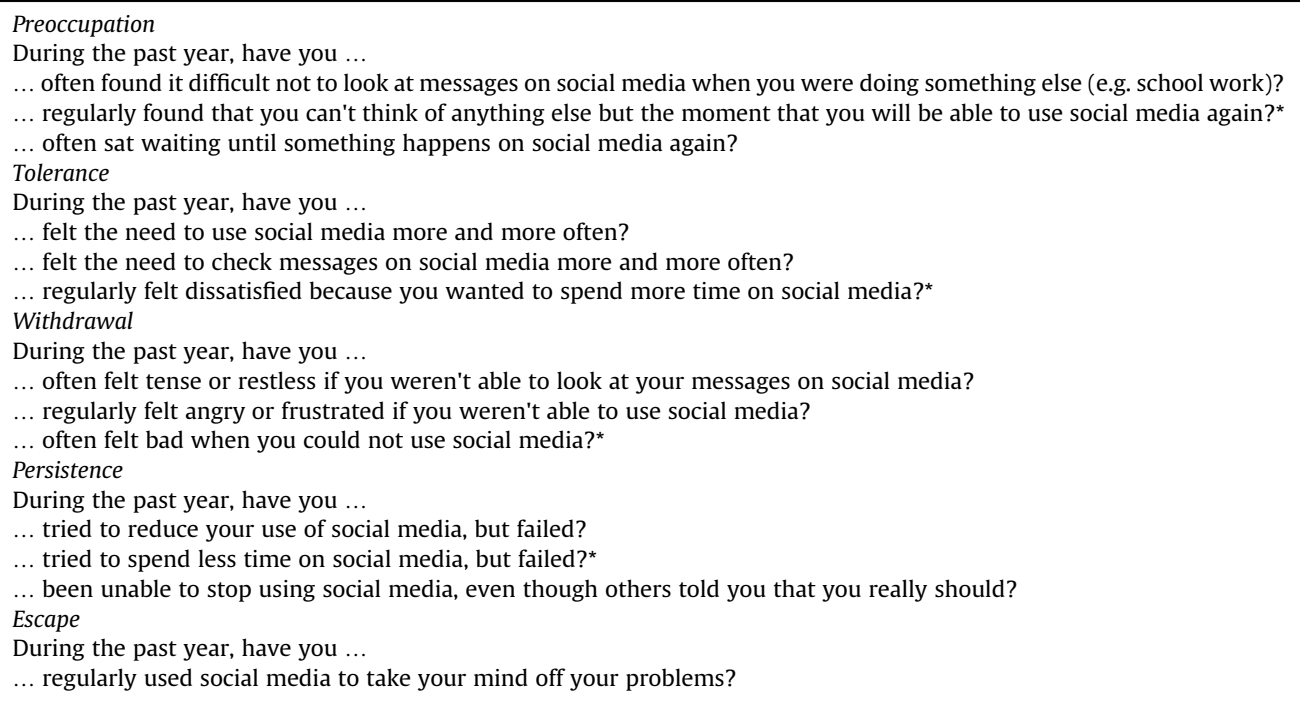


(continued)

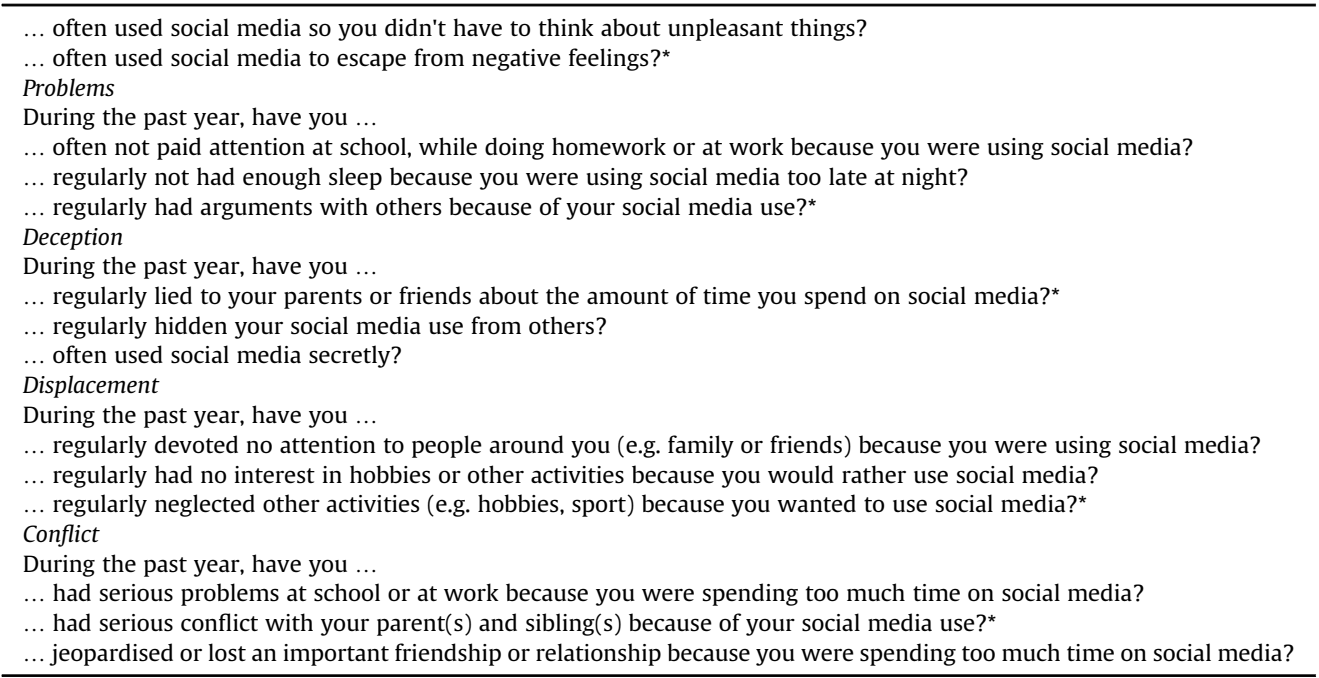

\section{References}

American Psychiatric Association. (2000). Diagnostic and statistical manual of mental disorders (4th ed.). Washington, DC: American Psychiatric Pub. Association. text revision.

American Psychiatric Association. (2013). Diagnostic and statistical manual of mental disorders (5th ed.). Washington, DC: American Psychiatric Association. text revision.

Asparouhov, T., \& Muthén, B. (2009). Exploratory structural equation modeling. Structural Equation Modeling: A Multidisciplinary Journal, 16(3), 397-438.

Billieux, J., Schimmenti, A., Khazaal, Y., Maurage, P., \& Heeren, A. (2015). Are we over pathologizing everyday life? A tenable blueprint for behavioral addiction research. Journal of behavioral addictions, 4(3), 119-123.

Brown, R. I. F. (1993). Some contributions of the study of gambling to the study of other addictions. In W. R. Eadington, \& J. A. Cornelius (Eds.), Gambling behavior and problem gambling (pp. 241-272). Reno, NV: University of Nevada.

Byrne, B. M. (2001). Structural equation modeling with AMOS: Basic concepts, applications and programming. Mahwah, NJ: Erlbaum.

Caplan, S. E. (2007). Relations among loneliness, social anxiety, and problematic Internet use. CyberPsychology \& Behavior, 10, 234-242.

Caplan, S. E. (2010). Theory and measurement of generalized problematic Internet use: a two-step approach. Computers in Human Behavior, 26(5), 1089-1097.

Cohen, J. A. (1960). A coefficient of agreement for nominal scales. Educational and Psychological Measurement, 20(1), 37-46.

Dalbudak, E., \& Evren, C. (2014). The relationship of Internet addiction severity with Attention Deficit Hyperactivity Disorder symptoms in Turkish University students; impact of personality traits, depression and anxiety. Comprehensive Psychiatry, 55(3), 497-503.

Demetrovics, Z., Urbán, R., Nagygyörgy, K., Farkas, J., Griffiths, M. D., Pápay, O., et al. (2012). The development of the problematic online gaming questionnaire (POGQ). PLoS ONE, 7. http://dx.doi.org/10.1371/journal.pone.0036417.

Dudley, R., Kuyken, W., \& Padesky, C. A. (2011). Disorder specific and transdiagnostic case conceptualisation. Clinical Psychology Review, 31(2), 213-224.

Flora, D. B., \& Curran, P. J. (2004). An empirical evaluation of alternative methods of estimation for confirmatory factor analysis with ordinal data. Psychological Methods, 9, 466-491. http://dx.doi.org/10.1037/1082-989X.9.4.466.

Gentile, D. A., Choo, H., Liau, A., Sim, T., Li, D., Fung, D., et al. (2011). Pathological video game use among youth: a two-year longitudinal study. Pediatrics, 127 319-329. http://dx.doi.org/10.1542/peds.2010-1353.

Glaros, A. G., \& Kline, R. B. (1988). Understanding the accuracy of tests with cutting scores: the sensitivity, specificity, and predictive value model. Journal of Clinical Psychology, 44, 1013-1023.

Griffiths, M. (1999). Internet addiction: fact or fiction? Psychologist, 12(5), 246-250.

Griffiths, M. (2005). A 'components' model of addiction within a biopsychosocial framework. Journal of Substance Use, 10, 191-197.

Griffiths, M., Van Rooij, A. J., Kardefelt-Winther, D., Starcevic, V., Király, O., Pallesen, S., et al. (2016). Working towards an international consensus on criteria for assessing Internet Gaming Disorder: a critical commentary on Petry, et al (2014). Addiction, 111(1), 167-175.

Griffiths, M. D., Kuss, D. J., \& Demetrovics, Z. (2014). Social networking addiction: an overview of preliminary findings. In Behavioral addictions. Criteria, evidence, and treatment (pp. 119-141). New York: Elsevier.

Griffiths, M., \& Szabo, A. (2013). Is excessive online usage a function of medium or activity? an empirical pilot study. Journal of behavioral addictions, 3(1), 74-77.

Hong, F., Huang, D. Lin, H., \& Chiu, S. (2014). Analysis of the psychological traits, Facebook usage, and Facebook addiction model of Taiwanese university students. Telematics and Informatics, 31, 597-606.

Hooper, D., Coughlan, J., \& Mullen, M. (2008). Structural equation modelling: guidelines for determining model fit. Electronic Journal of Business Research Methods, 6, 53-60.

Huang, Z., Wang, M., Qian, M., Zhong, J., \& Tao, R. (2007). Chinese internet addiction inventory: developing a measure of problematic internet use for Chinese college students. Cyberpsychology \& Behavior, 10, 805-811. http://dx.doi.org $10.1089 / \mathrm{cpb} .2007 .9950$.

Hu, L. T., \& Bentler, P. M. (1999). Cutoff criteria for fit indexes in covariance structure analysis: conventional criteria versus new alternatives. Structural Equation Modeling, 6, 1-55. http://dx.doi.org/10.1080/10705519909540118.

Kardefelt-Winther, D. (2015). A critical account of DSM-5 criteria for internet gaming disorder. Addiction Research \& Theory, 23(2), 93-98.

Kessler, R. C., Adler, L., Ames, M., Demler, O., Faraone, S., Hiripi, E. V. A., et al. (2005). The World Health Organization Adult ADHD Self-Report Scale (ASRS): a short screening scale for use in the general population. Psychological Medicine, 35(02) $245-256$.

Kietzmann, J. H., Hermkens, K., McCarthy, I. P., \& Silvestre, B. S. (2011). Social media? Get serious! Understanding the functional building blocks of social media. Business Horizons, 54(3), 241-251.

King, D. L., Haagsma, M. C., Delfabbro, P. H., Gradisar, M., \& Griffiths, M. D. (2013) Toward a consensus definition of pathological video-gaming: a systematic review of psychometric assessment tools. Clinical Psychology Review, 33(3), $331-342$.

Koc, M., \& Gulyagci, S. (2013). Facebook addiction among Turkish college students: the role of psychological health, demographic, and usage characteristics. CyberPsychology, Behavior, and Social Networking, 16, 279-284.

Kuss, D. J., \& Griffiths, M. D. (2012). Internet gaming addiction: a systematic review of empirical research. International Journal of Mental Health and Addiction, 10(2), $278-296$.

Kuss, D. J., Van Rooij, A. J., Shorter, G. W., Griffiths, M. D., \& Van de Mheen, D. (2013) Internet addiction in adolescents: prevalence and risk factors. Computers in Human Behavior, 29(5), 1987-1996.

Landis, J., \& Koch, G. (1977). The measurement of observer agreement for categorica data. Biometrics, 33, 159-174.

LeBlanc, J. C., Almudevar, A., Brooks, S. J., \& Kutcher, S. (2002). Screening for adolescent depression: comparison of the Kutcher adolescent depression scale with the Beck depression inventory. Journal of Child and Adolescent Psychopharmacology, 12(2) 113-126. http://dx doi.org/101089/104454602760219153.

Lemmens, J. S., Valkenburg, P. M., \& Gentile, D. A. (2015). The internet gaming disorder scale. Psychological Assessment, 72, 567-582. http://dx.doi.org/10.1037| pas0000062.

Lemmens, J. S., Valkenburg, P., \& Peter, J. (2009). Development and validation of a game addiction scale for adolescents. Media Psychology, 12, 77-95. http:// dx.doi.org/10.1080/15213260802669458.

Lemmens, J. S., Valkenburg, P. M., \& Peter, J. (2011). The effects of pathological gaming on aggressive behavior. Journal of Youth and Adolescence, 40, 38-47.

Lubke, G., \& Muthén, B. (2004). Factor-analyzing Likert scale data under the assumption of multivariate normality complicates a meaningful comparison of observed groups or latent classes. Structural Equation Modeling, 11, 514-534.

Marks, I. (1990). Behavioural (non-chemical) addictions. British Journal of Addiction, 85(11), 1389-1394.

McGraw, K. O., \& Wong, S. P. (1996). Forming inferences about some intraclass correlation coefficients. Psychological methods, 1(1), 30.

Meerkerk, G. J., Van den Eijnden, R. J. J. M., Vermulst, A. A., \& Garretsen, H. F. (2009). The compulsive Internet use scale (CIUS): some psychometric properties. 
CyberPsychology \& Behavior, 12(1), 1-6.

Mehdizadeh, S. (2010). Self presentation 2.0: narcissism and self-esteem on Facebook. Cyberpsychology, Behavior and Social Network Sites, 13, 357-364.

Odaci, H., \& Kalkan, M. (2010). Problematic Internet use, loneliness and dating anxiety among young adult university students. Computers and Education, 55 , 1091-1097.

Ophira, E., Nass, C., \& Wagner, A. D. (2009). Cognitive control in media multitaskers In Proceedings of the national academy of sciences of the United States of America, 106. September 15, 2009. Available at: http://www.pnas.org/content/106/37/ 15583.

Pantic, I. (2014). Online social networking and mental health. Cyberpsychology, Behavior, and Social Networking, 17(10), 652-657.

Petry, N. M., Rehbein, F., Gentile, D. A., Lemmens, J. S., Rumpf, H., Mößle, T., et al. (2014). An international consensus for assessing internet gaming disorder using the new DSM-5 approach. Addiction, 109(9), 1399-1406.

Raju, N. S., Bilgic, R., Edwards, J. E., \& Fleer, P. F. (1997). Methodology review: estimation of population validity and cross-validity, and the use of equal weights in prediction. Applied Psychological Measurement, 21(4), 291-305.

Rehbein, F., Kleimann, M., \& Mössle, T. (2010). Prevalence and risk factors of video game dependency in adolescence: results of a German nationwide survey. Cyberpsychology, Behavior and Social Network Sites, 13, 269-277. http:/ dx.doi.org/10.1089/cyber.2009.0227.

Rosenberg, M. Schooler, C., \& Schoenbach, C. (1989). Self-esteem and adolescent problems: modeling reciprocal effects. American sociological review, 1004-1018.

Rumpf, H. J., Meyer, C., Kreuzer, A., John, U., \& Meerkerk, G. J. (2011). Prävalenz de Internetabhängigkeit (PINTA). Bericht an das Bundesministerium für Gesundheit Verfügbar über. http://www.drogenbeauftragte.de/fileadmin/dateien-dba/ DrogenundSucht/Computerspiele_Internet/Downloads/PINTA-BerichtEndfassung_280611.pdf.

Russell, D., Peplau, L. A., \& Cutrona, C. E. (1980). The revised UCLA Loneliness Scale: concurrent and discriminant validity evidence. Journal of Personality and Social Psychology, 39, 472-480.

Ryan, T., Chester, A., Reece, J., \& Xenos, S. (2014). The uses and abuses of Facebook: a review of Facebook addiction. Journal of behavioral addictions, 3(3), 133-148.

Saaid, S. A., Al-Rashid, N. A. A., \& Abdullah, Z. (2014). The impact of addiction to Twitter among university students. In Future information technology (pp. 231-236). Springer Berlin Heidelberg.

Shotton, M. (1989). Computer addiction?: A study of computer dependency. London: Taylor \& Francis.

Soper, W. B., \& Miller, M. J. (1983). Junk-time junkies: an emerging addiction among students. The School Counselor, 31(1), 40-43.

Valkenburg, P. M., \& Peter, J. (2011). Adolescents' online communication: an integrated model of its attraction, opportunities, and risks. Journal of Adolescent Health, 48, 121-127.

Van Rooij, A. J., Ferguson, C., Van de Mheen, D., \& Schoenmakers, T. M. (2015)
Problematic Internet use: comparing video gaming and social media use [Conference Abstract]. Journal of Behavioral Addictions, 4(1), 1-62. http:/ dx.doi.org/10.1556/JBA.4.2015.Suppl.1.

Van Rooij, A., \& Prause, N. (2014). A critical review of "Internet addiction" criteria with suggestions for the future. Journal of behavioral addictions, 3(4), 203-213.

Van Rooij, A. V., \& Schoenmakers, T. M. (2013). Monitor Internet en Jongeren 20102012. Het (mobiele) gebruik van sociale media en games door jongeren [Monitor Internet and Youth 2010-2012: The (mobile) use of social media and games by adolescents]. http://www.ivo.nl/UserFiles/File/Publicaties/2013-01\%20Factsheet \%20Social\%20media\%20en\%20gamen.pdf.

Van Rooij, A. J., Schoenmakers, T. M., Van den Eijnden, R. J. J. M., \& Van de Mheen, D. (2010). Compulsive Internet use: the role of online gaming and other Internet applications. The Journal of Adolescent Health, 47(1), 51-57.

Van Rooij, A. J., Schoenmakers, T. M., Van den Eijnden, R. J. J. M., Vermulst, A. A., \& Van de Mheen, D. (2012). Video game addiction test: validity and psychometric characteristics. Cyberpsychology, Behavior, and Social Networking, 15(9), 507-511.

Van den Eijnden, R. J. J. M., Meerkerk, G., Vermulst, A. A., Spijkerman, R., \& Engels, R. C. M. E. (2007). Online communication, compulsive Internet use, and psychosocial well-being among adolescents: a longitudinal study. Developmental Psychology, 44, 655-665.

Van der Schuur, W. A., Baumgartner, S. E., Sumter, S. R., \& Valkenburg, P. M. (2015). The consequences of media multitasking for youth: a review. Computers in Human Behavior, 53, 204-215.

Wallis, C. (2006). The multitasking generation. Time Magazine, 167(13), 48-55.

Wallis, C. (2010). The impacts of media multitasking on children's learning \& development. New York: Joan Ganz Cooney Center.

Wang, C., Lee, M. K. O., \& Hua, Z. (2015). A theory of social media dependence: evidence from microblog users. Decision Support Systems, 69, 40-49.

Weinstein, A., \& Lejoyeux, M. (2010). Internet addiction or excessive internet use. The American journal of drug and alcohol abuse, 36(5), 277-283.

Wu, A. M. S., Cheung, V. I., Ku, L., \& Hung, E. P. W. (2013). Psychological risk factors of addiction to social networking sites among Chinese smartphone users. Journal of Behavioral Addictions, 2(3), 160-166.

Yen, J. Y., Ko, C. H., Yen, C. F., Wu, H. Y., \& Yang, M. J. (2007). The comorbid psychiatric symptoms of Internet addiction: attention deficit and hyperactivity disorder (ADHD), depression, social phobia, and hostility. Journal of Adolescent Health, 41(1), 93-98.

Young, K. (1996). Internet addiction: the emergence of a new clinical disorder. In Paper presented at the 104th annual meeting of the American Psychological Association. Toronto, Ontario, Canada.

Yu, C. Y., \& Muthén, B. (2002). Evaluation of model fit indices for latent variable models with categorical and continuous outcomes (Technical Report). Los Angeles: University of California at Los Angeles, Graduate School of Education \& Information Studies. 